\title{
The Impact of Mean Time between Disasters on Inventory Pre-positioning Strategy
}

Purpose - This paper addresses the impact of Mean Time Between Disasters (MTBD) to inventory pre-positioning strategy of medical supplies prior to a sudden-onset disaster.

Design/methodology/approach - We developed a trade-off model based on the operations of Médecins Sans Frontières (MSF) and implemented this in a spreadsheet-based platform to show the impact of MTBD on determining a pre-positioning strategy. This spreadsheet model identifies the most cost-efficient scenario out of a set of predefined pre-positioning scenarios. We implemented the model using a case study of a cholera outbreak in Zimbabwe.

Findings - We are able to show the impact of MTBD on determining the pre-positioning strategy. In addition, we also capture the trade-off decisions in transport modes and end-of-shelflife policies. Moreover, from financial perspective, we show that an interaction between relief (emergency) and development (regular) programs can be beneficial.

Research limitations/implications - We have some limitations on data access and availability. Some data (e.g. uncertainty in needs and lead-time) have to be collected for future research and, then, used to refine such decisions.

Practical implications - The model can be used as a justification for selecting an inventory prepositioning strategy based on mean time between disasters (MTBD).

Originality/value - We introduce relevant factors in a humanitarian organization's practice that have not yet received attention in literature (i.e. MTBD, inventory swap, and trade-off decisions in transport modes and end-of-shelf-life policies).

Keywords: mean time between disasters (MTBD), inventory pre-positioning, humanitarian logistics, inventory swap, shelf life

Article Classification: Case study

\section{Introduction}

To save lives in case of a disaster, a timely response is critical. In fact, the first few days after the outburst of a disaster are decisive, since the likelihood of survival beyond that time window diminishes significantly (Salmeron and Apte, 2010). Keeping an inventory of emergency supplies (also referred to as inventory pre-positioning) can be an effective mechanism for improving the response time to disasters and increasing the capacity of relief operations, resulting in a better response to minimize human suffering due to lack of supplies (Duran et al., 2011; Rawls and Turnquist, 2011; Van Wassenhove, 2006).

In this paper we focus at inventory prepositioning of medical supplies at Médecins Sans Frontières (MSF). MSF provides medical assistance to people affected by armed conflict, epidemics, disasters and exclusion from healthcare. Drugs constitute approximately $65 \%$ of total supply volumes of MSF in financial terms (MSF-OCA, 2008). Once drugs are close to expiry they can be donated to other parties. Otherwise they expire, in which case the medicines need to be disposed of. Disposals or donations have negative financial effects because they result in 
inventory write-offs. To avoid disposal or donation, MSF has to determine the most costefficient prepositioning scenario. MSF Operation Centre Amsterdam (MSF-OCA) and VU University Amsterdam collaborated on a project to evaluate the inventory prepositioning strategy. We identified that the Mean Time Between Disasters (MTBD), a period between two successive disaster strikes, is a key influential factor in the strategy's success. Our research focused on the impact of MTBD on determining a desired scenario as MSF pre-positioning strategy. To elucidate this impact, we developed a spreadsheet model, which concurrently may be used as a reference for allocating budget to implement the strategy.

We structured the remainder of the paper as follows: the next section of the paper describes the current inventory pre-positioning strategy at MSF, and includes the factors that affect the strategy. We then describe our model to identify the impact of MTBD to MSF inventory prepositioning strategy and to evaluate the strategy. Subsequently, we present and discuss the application and results of the model for the 2008 cholera outbreak in Zimbabwe. Finally, we conclude and discuss future work.

\section{Inventory Pre-positioning Strategy at MSF}

Humanitarian organizations usually run development and relief programs simultaneously (Besiou et al., 2012). Development programs, such as supporting hospitals operations (e.g. providing medicines), are characterized by more stable and predictable product needs over a longer period (Besiou et al., 2012; Kovács and Spens, 2007; Tomasini and Van Wassenhove, 2009). Development programs are at MSF referred to as regular programs. On the other hand, (emergency) relief programs, such as responding to cholera outbreaks, focus on response operations in the immediate aftermath of a disaster and are therefore typically characterized by a considerable uncertainty in needs (Besiou et al., 2012; Kovács and Spens, 2007; Tomasini and Van Wassenhove, 2009). At MSF, emergency relief programs consist of emergency preparedness and emergency response. While emergency preparedness focuses on the preparation phase of a disaster, emergency response focuses on the response phase of a disaster.

Part of emergency preparedness is inventory pre-positioning. Richardson et al. (2010) define inventory pre-positioning as a strategic decision to keep inventory of emergency supplies in preparation of disasters response. At MSF inventory pre-positioning is referred to as EPREP.

The EPREP process starts with an identification of potential medical emergencies or potential disasters and an estimation of a number of people who might be affected by disasters in a Mission. Mission is an MSF term for an operational unit that provides medical assistance in potentially affected areas of a country (MSF-OCA, 2008). The unit typically operates in countries, such as Zimbabwe and Haiti where expected impacts of disasters exceed their governments' expertise. MSF carries out the identification and the estimation processes based on similar past experiences, environment conditions and other contextual considerations in the Mission.

Based on the potential medical emergencies or disasters, MSF defines key items that should be present in the Mission in case of disaster. The definition of key items considers two aspects: medical and logistical. A key item from a medical perspective refers to its medical necessity, whilst from a logistical perspective it refers to its availability and transportation cost. An item such as Ringer Lactate is critical for cholera treatment and could be considered a key item from both perspectives. It is medically essential because severely dehydrated patients need Ringer 
Lactate to survive and it is also expensive to transport due to the item's weight and volume required (MSF-OCA, 2008). The total amount of Ringer Lactate in the treatment for an adult is e.g. $200 \mathrm{ml} / \mathrm{kg}$ or around 10 to 15 liters during the first 24 hours.

In order to be prepared for disaster, MSF locates inventory of key items in the Mission; these items are referred to as EPREP items. It is often possible to obtain the key items from the local suppliers in the Mission. However, MSF qualification scheme for drugs determines for most countries that the pharmaceutical items need to be purchased through headquarter to ensure products quality. There are four organizational supply levels involved in the order and delivery process of EPREP items from and to the Mission (see Figure 1):

1. Project site.

This level is directly responsible for the medical treatments of the patients.

2. Project base.

This level processes the order from project site, as well as delivers goods to project site, and coordinates with the project site and Mission Coordination.

3. Mission Coordination.

This is the center of supply coordination, processing the majority of order lines and goods. Mission Coordination is responsible for creating the EPREP plan and for determining EPREP stock level. The warehouse for EPREP items is normally also located in this level.

4. International supply center or Headquarter.

This is the main source of key items; it supplies the items to the Mission based on purchase requests. MSF -OCA is an example of a Headquarter.

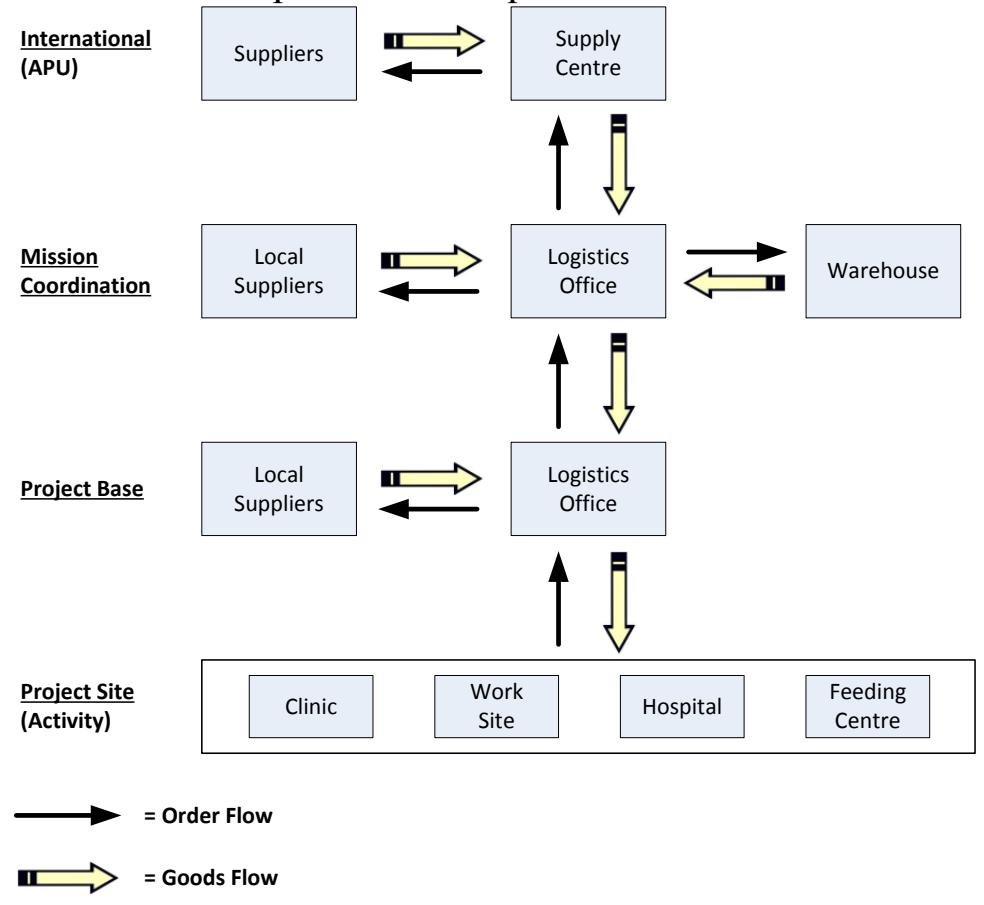

Figure 1 MSF-OCA organizational supply levels (source: MSF-OCA, 2008)

The order-to-delivery process starts at the project site with a forecast of needs that have to be covered by EPREP stock. The forecast is based on an estimate of the number of people that 
might be affected by potential medical emergencies or disasters in the area supported by the Mission. The project base then verifies and processes the forecast into a purchase order for initial stocking. Mission Coordination sends the purchase orders to Headquarter. Subsequently, Headquarter processes the order. From the Headquarter, the items are sent to Mission Coordination. After passing Mission Coordination, the supplies are stored in the warehouse until they are requested by the project sites. In the context of emergency pre-positioning, the delivery to the site is done when a disaster occurs.

For initial stocking, MSF uses sea freight to transport the EPREP items from the Headquarter to the Mission because it is cheaper than air transport per unit transported. Moreover, transport activities between disasters are categorized as non-urgent transport. Therefore, a short order-todelivery time and high levels of flexibility are not required.

The level of EPREP inventory needed in a Mission depends on the transport mode used for sending additional supplies for emergency response from the Headquarter to the Mission's warehouse. Once a disaster has occurred, replenishment is necessary because pre-positioned inventory, in general, cannot cover all needs during disaster relief activities. When no disaster occurs, the pre-positioning stock is not used and will expire if not used otherwise. The slower the transport mode used to send the additional supplies for emergency response, the longer the average lead-time and as a result, the more inventory needs to be stored in the Mission's warehouse and the higher the risk of obsolescence. If sea transport is used for sending additional supplies for emergency response after a disaster has occurred, the volume of initial EPREP inventory needs to be higher compared to a situation in which air transport with shorter leadtimes were used. However, sea transport costs per unit are lower than air transport costs. Additionally, the transport cost, in the aftermath of a disaster, often increases significantly (de Leeuw et al., 2010). As a result, transport costs need to be traded off with inventory and obsolescence costs due to limitations in the local inventory's shelf life.

MSF has two end-of-shelf-life policies for its EPREP items. The items can either be disposed of or be donated. Disposing medical products - many of them being chemical waste - is possible but poses risks. Practice shows that often government regulations are in place to dispose of medicines. Disposal practices of countries are not always as desired, nor are facilities available to properly dispose of the items, especially in developing countries (Coker et al. 2009; Diaz et al. 2005). Another drawback of this alternative is that typically MSF has to pay for costs associated with every disposed of item. Replenishment of local stock takes place whenever MSF disposes of its items.

The second policy is to donate the inventory to other parties (e.g. countries and agencies) prior to expiry. According to MSF regulations, donations should take place at least six months prior to expiry. Similar to disposals, donations require replenishment of the local stock. In fact, by donating MSF may face more frequent replenishments than if disposals were to be used, since the remaining shelf life until donation is shorter than the remaining shelf life until disposal because donation takes place at least 6 months before expiry and disposal only when items are expired. This will lead to an increase in replenishment costs, which will need to be traded off with disposal costs.

The decision to choose between expiry and donation is based on financial consideration as well as on non-monetary deliberations (e.g. ethics, security, or political aspects). Suppose there is a 
huge shortage of drugs in a Mission country, MSF could not easily decide to dispose the expired drugs. People might create a non-conducive movement (e.g. demonstration and terror) and politicians might make the bureaucracy even more difficult (e.g. postponement in the custom) for MSF if they are aware that MSF destroy expired drugs. Even if these drugs are available on the local market, the quantity is often limited and the quality is often poor. Therefore, these aspects could make MSF choose for donation rather than disposal.

\section{Model}

The configuration of MSF pre-positioning strategy is determined by trading off two decisions as explained in the previous section: 1. transport modalities (sea freight or airfreight) 2. end-ofshelf-life policy. The end-of-shelf-life policy offers two options as well: disposal or donation. By taking into account the donation policy, the model indirectly consider the non-monetary deliberation and financial consequences of this policy.

We therefore consider four possible configurations called EPREP scenarios (see Table 1).

Table 1 MSF EPREP scenarios

\begin{tabular}{|c|c|c|}
\hline Scenario & $\begin{array}{c}\text { Transport Mode after } \\
\text { disaster strikes }\end{array}$ & End-of-Shelf-Life \\
\hline 1 & Sea & Donate \\
\hline 2 & Sea & Dispose \\
\hline 3 & Air & Donate \\
\hline 4 & Air & Dispose \\
\hline
\end{tabular}

MSF can decide to perform inventory swaps. In this case EPREP stock that is close to expiry can be swapped with fresher stock from the MSF regular programs. This may enable stock pooling since items used in regular programs are often similar to those used in emergency relief. Second, replenishment of regular programs take places relatively frequently with multiple replenishments during the remaining shelf life of the EPREP items. Stocks close to expiry will therefore be used in regular programs and EPREP stock will be fresher. Third, from a financial point of view, MSF can physically swap the items between EPREP and regular program stock without reallocation funding. This strategy is different from the concept of the "Sell-One-Store-One" (SoSo) inventory strategy introduced by Sheffi (2001). According to the SoSo inventory strategy stocks are designated to anticipate an extreme disruption (e.g., terrorist attack or natural hazard); one should replenish the inventory immediately if it is used to anticipate a fluctuation in day-to-day business. In the implementation of inventory swap, MSF indeed has to replenish the EPREP stock with an equal amount as taken for regular program. However, inventory swap is not performed to maintain any MSF regular programs, even if a critical incident happens to the regular program, as it is performed purely to increase the shelf life of the EPREP stock. In the other words, SoSo replenishments are triggered based on use instead of based on shelf life/expiry as in the inventory swap. We will also consider inventory swaps for each scenario.

MSF aims to allocate its budget efficiently to prevent excess expenditure and to ensure continuity of its pre-positioning strategy. Additionally, since time between disasters is uncertain, we can only use averages as an estimate to approach the problem deterministically. Therefore, we use Mean Time Between Disasters (MTBD) as a key influential factor in identifying the lowest cost scenarios. MTBD is the average time lapse between two successive disaster strikes. 
The MTBD concept is similar to the Mean Time Between Failures (MTBF) concept which can be found in manufacturing or engineering literature (e.g. Lu et al., 1994). In manufacturing, a machine failure is unpredictable. MTBF is one of factors that affect the decision making process in determining a stock strategy to respond to the failure. In other words, different MTBFs may determine different strategies.

We built a trade-off model to show how MTBD affected the decision making process on determining MSF pre-positioning strategy. We have developed the model in line with MSF EPREP planning practices to evaluate each scenario and calculate all relevant trade-offs as explained earlier. The EPREP process starts with initial stocking of EPREP items in a Mission's warehouse and ends when an emergency response program takes over the aid actions. If EPREP items cannot cover the scale of the disaster that strikes the Mission's country, the emergency response program in the Mission orders emergency kits and other additional supplies from the Headquarter. In this case, the emergency response program arranges a delivery plan, which is executed by using sea shipments at the onset of a disaster. As a result, in the air scenarios (i.e. scenario 3 and 4), air cargo will be used to fly in additional items to cover the needs during the period between air and sea transport lead-time, until the arrival of additional supplies for emergency response using the sea shipments. Figure 2 illustrates the scope of an EPREP scenario.

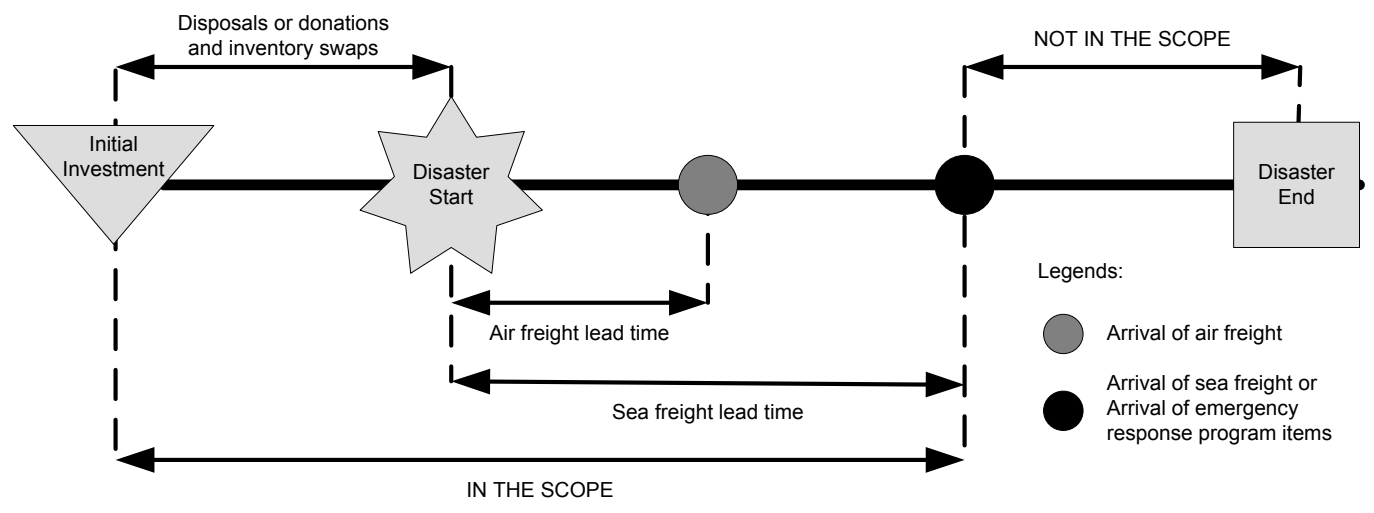

Figure 2 Scope of each EPREP scenario

To show inventory movements over time for each scenario related to the scope in Figure 2, we created Figure 3. The horizontal axis shows time, while the vertical axis shows the inventory level. On the horizontal axis, we put relevant events that trigger an inventory movement (i.e., inventory swap, donation, disposal, replenishment, and disaster). The blocks in Figure 3 represent stocks in the warehouse. The light grey blocks show EPREP stock from inventory swap, the dark grey blocks show EPREP stock from replenishment and black blocks show additional items to cover the needs during the period between air and sea transport lead-time after a disaster. The number inside the blocks shows the sequence of the EPREP items' arrival in the warehouse. To identify the items that need to be taken out first, we use a First Expiry First Out (FEFO) principle. As a result, blocks with the smallest number have to be taken out first. 


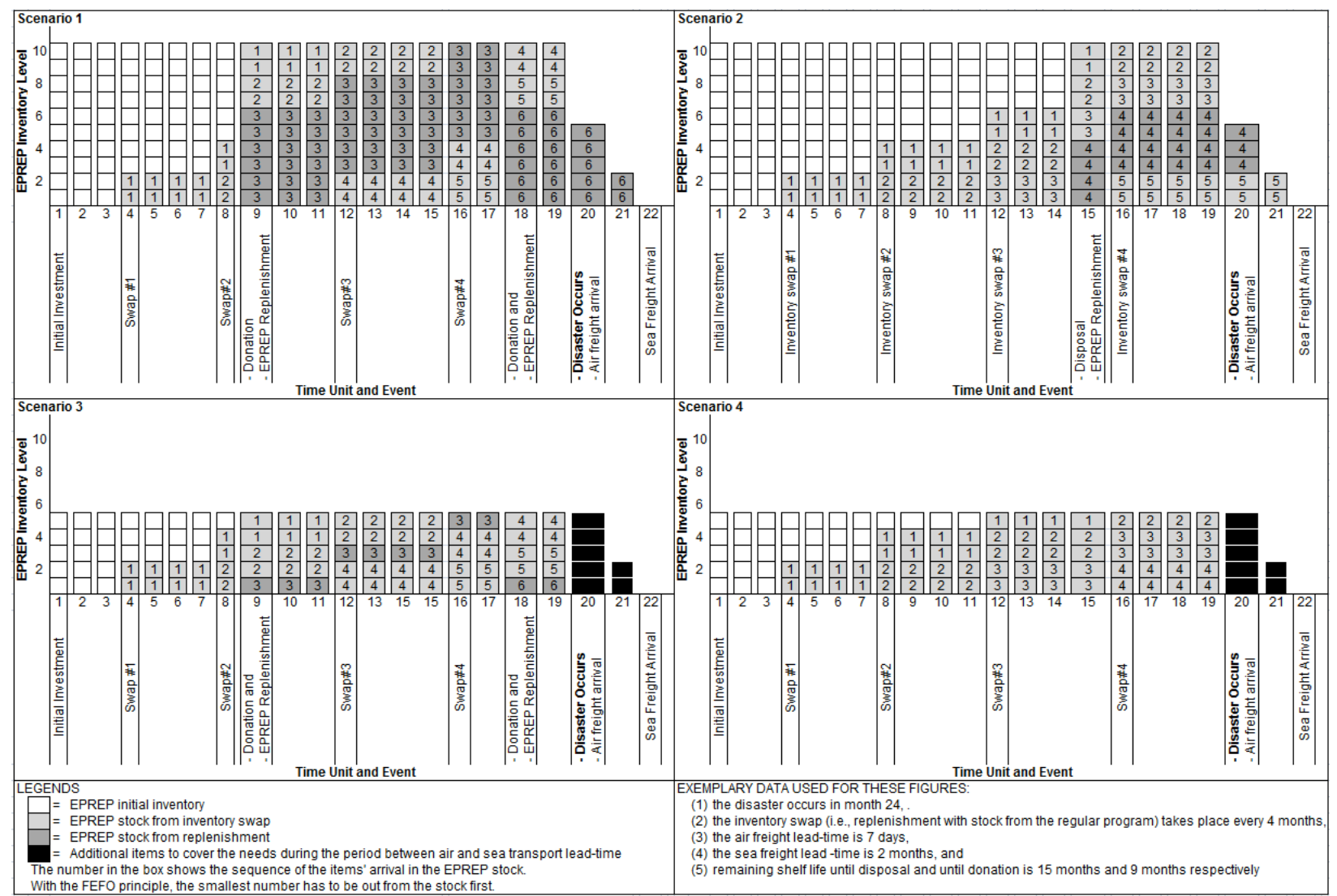

Figure 3 Inventory movement of EPREP item

We calculate the total cost of each scenario for different MTBD levels and plot the result in graphs. We then compare the total costs of all scenarios by performing breakeven analysis for every set of scenarios. We include all relevant costs, including initial investment (i.e. the costs needed to provide EPREP items for the first time in the inventory), transportation costs, disposal costs, replenishment costs, and holding costs. We assume no costs are involved in donating the items as MSF usually donates the item locally in the Mission country and the recipients sometimes collect the donation directly from MSF's warehouse. We only consider the breakeven points that render the lowest total cost at a certain MTBD level. The preferred scenario is obviously the one that renders the lowest total cost for a specific MTBD level or over a period between breakeven points.

We built our trade-off model in a spreadsheet-based platform. One benefit of creating the model in this platform is that our model considers relevant MSF EPREP factors as well as allows for easy tracking, analysis and comparisons. A further benefit is that the model requires no additional financial or training investment. Excel spreadsheets are widely used in business today, including MSF. A third benefit is that by using a spreadsheet as a platform for the model, the users benefit from additional flexibility and reliability (Guerrero, 2010; Mather, 1999). In addition, this platform allows the model to be shared easily among staff. At MSF most supply chain people are familiar with a spreadsheet and are expected to be able to use the model with relatively little training.

Our model can be used as a justification for selecting an inventory pre-positioning strategy. The cost effects of the transport mode used (which will affect the EPREP stock level), the end-of- 
shelf life decision, and related to the latter the use of inventory swaps. Using a spreadsheet platform, different strategies can be simulated dependent on the MTBD, for different products and/or different countries. Before the model identifies the best scenario for specific outbreak/disaster, the user should provide information on the supply chain (e.g., lead-time for each mode of transport, holding cost, etc.) and on the key item investigated (e.g., shelf life, price, weight, etc.). Using the model, the scenarios can be justified by analyzing the breakeven points and using a what-if approach. While the breakeven analysis is used to see when a scenario is more preferable than other scenarios, a what-if approach is used to draw a conclusion about which scenario needs to be selected with regard to a certain situation (e.g., what to do if the MTBD of a cholera outbreak is 2 years). In the end, the user will be able to determine the best scenario for specific or any MTBD levels as well as the total cost and other relevant details (e.g., average annual replenishment quantity). These details are important should the user want to use other criteria as the main consideration for the best scenario.

We gathered all necessary data to develop the model from MSF regular data sources (e.g. transactional data, data on suppliers' performance, and list of key medical items). In addition, MSF's logistics officers and medical staff provided additional information. While logistics officers provided information related to the procurement and replenishment of emergency items (e.g. transport lead-time, shelf-life of the items, items' price, and price increase during emergency), medical staff provided information on potential needs (e.g. needs when a disaster strikes). The available data is limited and thus we were forced to focus on a deterministic setting with a single product and disaster consideration.

We implemented the model using real data from a case study of cholera outbreaks at Zimbabwe in 2008. Data related to inventory pre-positioning for the outbreak, as well as all other data used may be found in Appendix A. After implementation, MSF's experts validated the model and we performed sensitivity analyses to demonstrate the robustness of the model developed.

\section{Implementation and Validation}

\section{Cholera Outbreak, Zimbabwe 2008}

The cholera outbreak started in August 2008 around Harare, Zimbabwe's capital, followed in October 2008 by a rapid increase in cases. A total of 98,309 cumulative cases and 4,283 deaths had been reported by May 2009, with the average case fatality rate of 4.4\% (IFRC, 2009).

Prior to the 2008-cholera outbreak, MSF had been supporting hospital operations and running $\mathrm{HIV}$ and malnutrition programs in Zimbabwe. Since cholera is endemic to certain rural areas in Zimbabwe, MSF had concurrently been preparing for a possible cholera outbreak. MSF ensured that Ringer Lactate, essential in battling severely dehydrated patients, was stocked for emergency pre-positioning purposes. For this reason, MSF was able to respond quickly when the cholera outbreak started in 2008. It did so by deploying its Cholera Treatment Centres (CTCs) (MSF, 2008). CTCs are specialized isolation wards located in project sites which provides efficient treatments for cholera victims and prevents spreading (MSF, 2013). We applied the model to this particular case.

Results 
We present two outcomes of the model on the case of 2008 cholera outbreak in Zimbabwe. We present total costs of EPREP scenarios in Figure 4. The total cost of each scenario is calculated with the following equation:

For every scenario $i$ with MTBD level $T$ :

$T C_{i}=I_{i}+R_{\text {post }_{i}}+\sum_{j=1}^{T}\left(R_{\exp _{i j}}+D_{i j}+H_{i j}\right)$

Where:

$T C_{i} \quad=$ Total cost of scenario $i$

$I_{i} \quad=$ Initial investment of scenario $i$.

$R_{\text {post }_{i}}=$ Cost for additional supplies in the period between air and sea transport lead-time after disaster of scenario $i$.

$R_{\exp _{i j}}=$ Replenishment cost due to expiry of scenario $i$ at period $j$.

$D_{i j} \quad=$ Disposal cost of scenario $i$ at period $j$

$H_{i j} \quad=$ Holding cost of scenario $i$ at period $j$.

As can be seen in Figure 4, the initial investment, disposal, replenishment, and holding costs of sea freight scenarios (i.e. scenario 1 and 2) are higher than airfreight scenarios (i.e. scenario 3 and 4). However, airfreight scenarios have to spend on additional expense for post-disaster replenishment to cover needs during the gap between sea and air transport lead-time as explained in the Model section. 


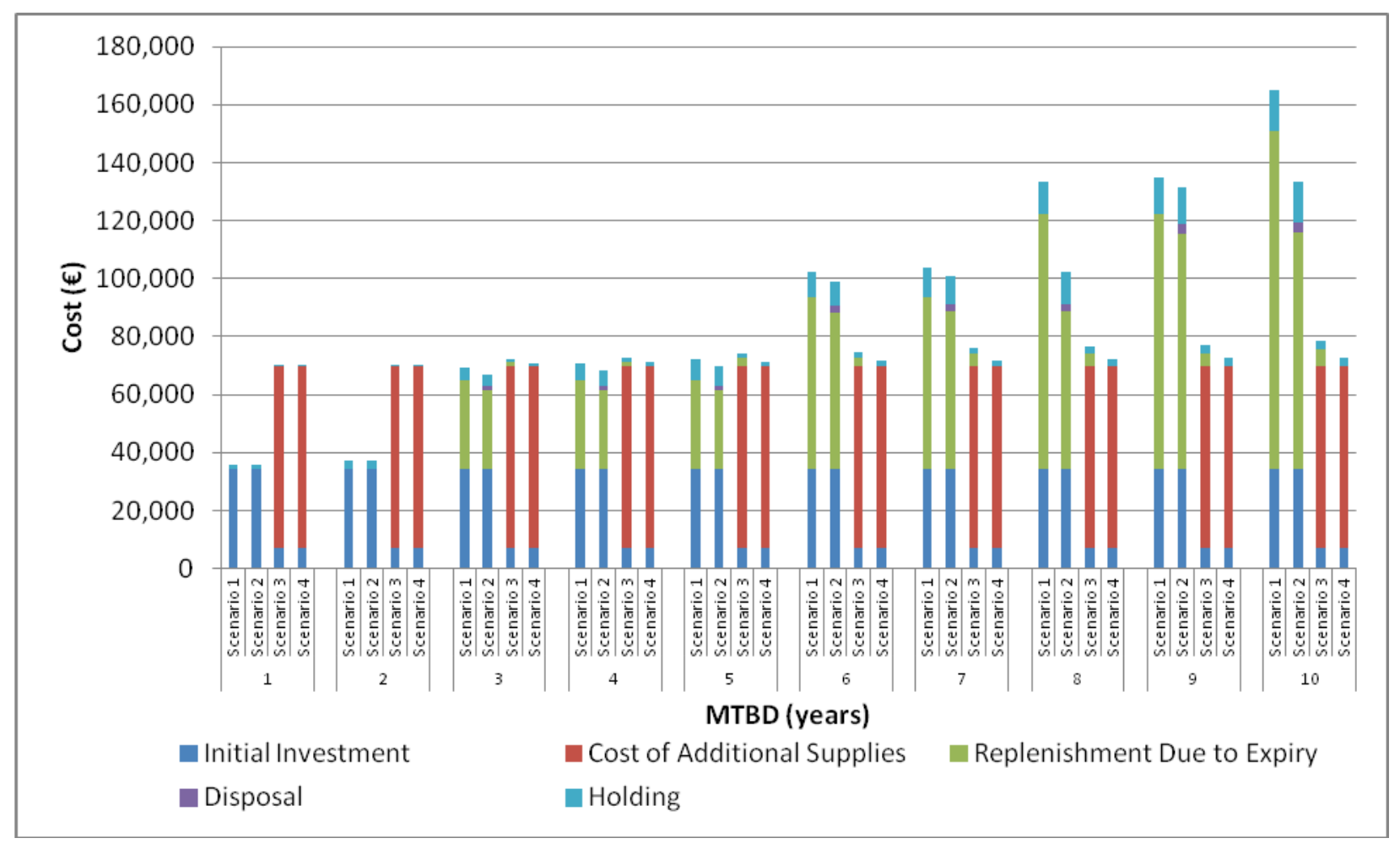

Figure 4 Total costs of EPREP scenarios

Together with the initial investment, the cost for additional supplies (in the period between air and sea transport after the disaster) is a "one-time" expense. We define the sum of the initial investment and replenishment cost after the disaster as 'initial cost', which is equal to the minimum cost needed to implement a scenario. The initial cost of the airfreight scenarios $(€$ $69,816)$ is larger than for the sea freight scenarios (€ 34,416). Replenishment cost after the disaster contributes the most to the initial cost of airfreight scenarios, and over $80 \%$ of it entails transportation costs.

Table 2 provides a breakeven matrix of EPREP scenarios. As can be seen in Figure 4 the breakeven point between scenario 1 and 2 is between MTBD of two and three years. Table 2 shows that the breakeven point is at MTBD of 2.25 years. At this point, the total cost of these scenarios is the lowest of the four scenarios, and equals $€ 37,990$. Not all of the breakeven points, however, render the lowest total cost at a specific MTBD level; only the breakeven points of scenario 1 and 2 and of scenario 2 and 4 at the MTBD of 5.51 years (see the highlighted cells in Table 2). Based on this matrix and further analysis, the user can make decisions on the preferred scenario. The next section will explain the implication of these results in more detail.

Table 2 Breakeven points of of EPREP scenarios

\begin{tabular}{|c|c|c|c|c|c|}
\hline \multicolumn{6}{|c|}{ 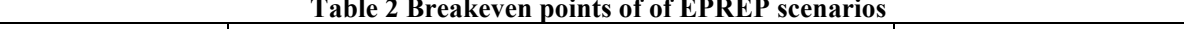 } \\
\hline \multirow{2}{*}{ Scenario } & \multicolumn{4}{|c|}{ Scenarios } & \multirow{2}{*}{ Remarks } \\
\hline & 1 & 2 & 3 & 4 & \\
\hline \multirow{2}{*}{1} & & 2.25 & 4.55 & 4.52 & MTBD (Year) \\
\hline & & 37,990 & 72,922 & 71,327 & Total cost $(€)$ \\
\hline 2 & & & 5.61 & 5.51 & MTBD (Year) \\
\hline
\end{tabular}




\begin{tabular}{|c|c|c|c|c|c|}
\hline \multirow{2}{*}{ Scenario } & \multicolumn{4}{|c|}{ Scenarios } & \multirow{2}{*}{ Remarks } \\
\cline { 2 - 5 } & $\mathbf{1}$ & $\mathbf{2}$ & $\mathbf{3}$ & $\mathbf{4}$ & \\
\hline \multirow{6}{*}{$\mathbf{3}$} & & 74,526 & $\mathbf{7 1 , 6 2 7}$ & Total cost $(€)$ \\
\hline \multirow{4}{*}{4} & & 2.25 & MTBD (Year) \\
\hline
\end{tabular}

\section{Findings and Implications}

Based on the trade-off issues and the results in Figure 4 and Table 2, several findings may be reported.

First, if the MTBD is smaller than the actual remaining shelf life of EPREP items, they will most likely be used in a response to a disaster before they expire. The longer the MTBD, the higher the holding, disposal, and replenishment costs of the EPREP items. Furthermore, the more inventories are stored locally, the higher expiry costs. Logically, transport modalities influence appropriate stock levels: sea freight scenarios require larger stock level and consequently have higher replenishment, disposal, and holding costs than air freight scenarios.

Secondly, at some MTBD level, the total cost of sea freight and airfreight scenarios is equal. These breakeven points refer to situations where the total cost between two scenarios is equal. Before this point sea freight scenarios have lower total cost; after this point, the total cost of sea freight scenarios exceeds the total cost of airfreight scenarios. For example, according to Table 2 the breakeven point of scenario 2 and 4 is at an MTBD of 5.51 years. Scenario 2 is preferable up to an MTBD of 5.51 years while after this point, the preferred scenario would be scenario 4 (see also Figure 4). As a result the MTBD affects the decision making process in determining optimal pre-positioning strategy configurations.

Thirdly, using the same transport mode, a disposal scenario is preferable over a donation scenario. The results in Table 2 and Figure 4 show that the total cost of scenario 1 and 2 is equal before the first donation, which takes place at MTBD of 2.25 years. Scenario 2 also renders the lowest cost up to MTBD of 5.51 years. As a result, MSF should choose scenario 2 over scenario 1 as it anticipates longer MTBD and more importantly provides the lowest cost. Similar to the situation between scenario 1 and 2, we also found that the total cost of scenario 3 and 4 is equal until the MTBD of 2.25 years. After MTBD of 2.25 years, MSF should choose scenario 4 over scenario 3 as it provides the lowest cost.

We can conclude that according to the above disposal scenarios are preferred over the donation scenarios (i.e. scenario 2 is preferable over 1 ; scenario 4 is preferable over 3 ). First, replenishment costs of disposal scenarios are smaller than donation scenario (see Figure 4). Second, the costs of disposing items are smaller than the difference in replenishment costs of both scenarios. This situation can be changed with higher disposal costs.

We performed comparisons of the EPREP scenarios with and without inventory swap to verify whether the swap is indeed beneficial. The result in Table 3 confirms that inventory swap helps 
MSF to reduce replenishment costs. Consequently, the disposal scenario has fewer replenishment cost than donation scenario.

\begin{tabular}{|c|r|r|}
\hline \multirow{2}{*}{ Tcenario } & \multicolumn{2}{|c|}{ Savings (in percentage) } \\
\cline { 2 - 3 } & Annual disposal cost & Annual replenishment cost \\
\hline 1 & - & 16.85 \\
\hline 2 & 34.68 & 21.62 \\
\hline 3 & - & 80.00 \\
\hline 4 & 100.00 & 100.00 \\
\hline
\end{tabular}

According to Human Rights Watch (2013), Harare residents had, after the 2008 cholera outbreak had ended in July 2009, still little access to potable water and sanitation services. The situation was to some extent better than before the outbreak. However, the residents continued to resort to drinking water from sewer-contaminated wells and defecating in bushes. As a result an additional 149 cholera cases had been reported in the period of September-December 2009 (WHO 2010). We thus assume that the MTBD of cholera outbreaks in Zimbabwe is equal to less than 1 year. Our results show that, in case of MTBD levels less than 5.51 years, MSF should implement scenario 2. With an MTBD of less than 1 year total cost are equal to $€ 35,841$. If MSF implement scenario 3 or 4 , costs are nearly double $(€ 70,116)$.

\section{Validation}

A limitation of the study is that no sufficient data exists to compare the real expenses to implement EPREP strategy to results from our model for the 2008 cholera outbreak case in Zimbabwe. However, an MSF logistics expert had evaluated all of the model outcomes and stated that they are in accordance with his expectations and the actions taken in preparation for the outbreak. For example, the preferred scenario in real life is the same as the one suggested by the model. The model helps the expert to verify his judgment with comprehensive calculations and cost associated with the preferred scenario. Another example is the effect of inventory swap on replenishment cost and disposal cost. According to the expert, inventory swaps are expected to be able to reduce the replenishment cost and disposal cost by raising the remaining shelf life of the EPREP items. Therefore, while insufficient data for comparison exists, on a practical level, the result of our model proves to support expert expectations and shows the substantial saving that result from early implementation of inventory swaps in the pre-positioning strategy.

\section{Sensitivity Analysis}

We performed sensitivity analysis on the impacts of the total cost and the scenario preference. As we saw in the preceding section, replenishment costs is the main factor that determines the selected scenario. Changes in the replenishment costs could alter the preferred scenario or the breakeven points. For the sensitivity analysis, we chose parameters that were expected to affect the replenishment costs. Accordingly, we chose the following parameters: sea transportation lead-time, transportation cost, items price, and inventory swap frequency and quantity.

We conducted a sensitivity analysis by changing the values of the aforementioned parameters one by one while keeping the other parameters values constant, as suggested by Zeng and Rosetti 
(2003). The results of the sensitivity analysis (see Table 4) show that the aforementioned parameters are proportional to the replenishment costs except for the inventory swap frequency and quantity. The changes in the replenishment costs affect the total cost and might alter the breakeven point of scenarios 2 and 4 .

The result of the sensitivity analysis shows that when changing the parameters, the preferred scenario remains the same. Concurrently, the breakeven point of scenarios 2 and 4 can be found earlier or later than the initial breakeven point of these scenarios (i.e. MTBD of 5.51 years, see Table 2). In the third finding of the Findings and Interpretation section, we observed that the proportion of the replenishment cost of scenario 2 to the transportation cost after a disaster of scenario 4 could be used as an estimator to identify the change in the second breakeven point. When this proportion increases, the breakeven point will be earlier than the initial breakeven point between scenario 2 and 4 (i.e. less than 5.51 years). Table 4 shows when to select scenario 4 based on the changes of the breakeven point of scenarios 2 and 4 .

\begin{tabular}{|l|c|c|}
\hline \multirow{2}{*}{ Tarameters } & \multicolumn{2}{c|}{ Breakeven point of scenarios 2 and 4 } \\
\cline { 2 - 3 } & $\begin{array}{c}\text { with 100\% of } \\
\text { parameter increase } \\
\text { (years) }\end{array}$ & $\begin{array}{c}\text { with 100\% of } \\
\text { parameter decrease } \\
\text { (years) }\end{array}$ \\
\hline Sea freight lead-time & 3.97 & 5.53 \\
\hline Transport cost per unit & 5.73 & 2.87 \\
\hline Item price & 2.90 & 5.64 \\
\hline Swap quantity & 5.40 & 5.59 \\
\hline Swap frequency & 5.34 & 5.55 \\
\hline
\end{tabular}

The change in sea transport lead-time affects the proportion that is explained earlier due to two reasons. First, sea transport lead-time will affect the quantities to cover the consumption in the period between air and sea transport after disaster strikes. The longer the lead-time of sea-freight requires more needs to be covered during this period and thus higher EPREP stocks. An increase of the sea freight lead-time, therefore, would move the breakeven point of scenarios 2 and 4 to an MTBD less than the initial breakeven point of 5.51 years. In a similar vein, a shorter sea transport lead-time will give the opposite effect.

Second, the change in sea transport lead-time affects the remaining shelf life of the EPREP items. The remaining shelf life of the items is inversely proportional with the replenishment costs. An increase of the sea freight lead-time, therefore, would shorten the remaining shelf life of the items and increase the initial stock quantities. As a result, the replenishment frequency and cost over a certain period would increase. In other words, the change in transport lead-time indirectly affects the replenishment costs of scenario 2 . The impact of this change in the transport cost of scenario 4 is small. An increase of the lead-time, therefore, would increase the proportion of the replenishment cost of scenario 2 to the transportation cost after a disaster of scenario 4 . An increase of the sea transport lead-time, therefore, would move the breakeven point of scenarios 2 and 4 earlier than the breakeven point $(<5.51$ years). On the other hand, a decrease of sea transport lead-time would decrease the proportion. 
The change in transport cost per unit, conversely, has a more substantial effect on transportation cost in scenario 4 than the effect on replenishment cost in scenario 2. Accordingly, the increase of this parameter would decrease the proportion of the replenishment cost of scenario 2 to the transportation cost after a disaster of scenario 4. An increase of the transport cost per unit, therefore, would move the breakeven point between scenario 2 and 4 later than before $(>5.51$ years). A decrease of transport cost per unit would increase the proportion. In addition, there is no significant change to the proportion when the swap quantity or frequency is altered.

\section{Discussions and Conclusions}

Our research focused on the impact of Mean Time between Disasters (MTBD) on determining a desired inventory pre-positioning scenario using a case from MSF. We identified the MTBD as a key influential factor in determining MSF inventory pre-positioning strategy configuration. The MTBD is analogous of mean time between failures (MTBF) in disaster preparedness. We formulated a trade-off model to show how MTBD affected the decision making process of determining a desired EPREP scenario (i.e. pre-positioning strategy configuration) out of a set of predefined scenarios. The model was able to determine the relation of the decisions on transport mode and end-of-shelf-life policy and make comparison among decisions dependent on the MTBD, which is important to identify the preferred scenario.

We implemented the model in a spreadsheet-based platform and applied the model to Zimbabwe's 2008 cholera outbreak. Although this spreadsheet-based evaluation procedure is established based on MSF situation, it can be revised easily. Thus, the model may be applicable to other humanitarian organizations, which are implementing the inventory pre-positioning strategy, with only few adjustments needed.

Based on our findings, MTBD could alter the decision on the preferred scenario. With gradual increases to the MTBD level, mainly due to replenishment cost, the total cost also increases gradually. This is because the items most likely could not be used to respond to a disaster due to expiry. In the case study performed we found that with MTBD levels lower than 5.51 years, if the decision is purely based on monetary considerations, MSF should implement scenario 2 (transport mode: sea transport; end-of-shelf-life policy: disposal). After this level (i.e. MTBD is over 5.51 years), scenario 4 is preferred. By implementing the preferred scenario, MSF has a potential savings that equals the gap between the total costs of the preferred scenario and other scenarios. We also verified that inventory swap is able to reduce the disposal and replenishment costs.

From an academic perspective, to our knowledge, this paper is the first to introduce the concept of MTBD and its effect on inventory prepositioning.. We show how MTBD affects the decision making process on determining pre-positioning strategy. To our knowledge, there is only one paper - i.e. Consuelos Salas et al. (2012) - that considers the shelf life of items in their inventory model. However, this study only considers disposal as end-of-shelf-life policy. Our model also considers donation as a viable option in humanitarian operations, especially when the operations have to deal with non-monetary aspects (e.g. ethics, security, and political aspects). We furthermore introduce inventory swaps as a way to limit disposals and donations.

The method employed is independent of funding structure. As such we expect it to be applicable to a diversity of situations. Our findings are restricted by the fact that it is difficult to exchange medicines between countries due to legislation issues. Furthermore, due to data limitations we 
were forced to focus on a deterministic setting with a single product and disaster. Thus, future research can be aimed at (1) the uncertainty of some parameters in the model, such as needs and lead-time, (2) multiple key items, which have different value density, for a disaster in our model, (3) multiple disasters. The research might investigate whether the humanitarian organization has to keep different scenario for different value density and or disaster or use one scenario for all items and or disasters.

\section{References}

Bazaraa, M.S., Sherali, H.D., and Shetty, C.M. (2006), Nonlinear programming: theory and algorithms (Hoboken; Ney Jersey: John Wiley \& Sons)

Besiou, M., Pedraza Martinez, A., and Van Wassenhove, L.N. (2012), "The effect of earmarked funding on fleet management for relief and development", INSEAD Working Paper No. 2012/10/TOM/INSEAD Social Innovation Centre, Vol.

Coker, A., Sangodoyin, A., Sridgar, M., Booth, C., Olomolaiye, P., and Hammond, F. (2009), "Medical waste management in Ibadan, Nigeria: Obstacles and prospects", Waste Management, Vol.29, No.2, pp. 804-811.

Consuelos Salas, L., Robles Cárdenas, M., and Zhang, M. (2012), "Inventory policies for humanitarian aid during hurricanes", Socio-Economic Planning Sciences, Vol. 46, No. 4, pp. 272-80.

de Leeuw, S., Kopczak, L.R., and Blansjaar, M. (2010), "What Really Matters in Locating Shared Humanitarian Stockpiles: Evidence from the WASH Cluster", in L.M. Camarinha-Matos, X. Boucher, and H. Afsarmanesh (eds.), Collaborative Networks for a Sustainable World (IFIP Advances in Information and Communication Technology, 336: Springer Berlin Heidelberg), pp. 166-72.

Diaz, L.F., Savage, G.M., and Eggerth, L.L. (2005), "Alternatives for the treatment and disposal of healthcare wastes in developing countries", Waste Management, Vol 25, No. 6, pp. 626-637.

Duran, S., Gutierrez, M.A., and Keskinocak, P. (2011), "Pre-Positioning of Emergency Items for CARE International", Interfaces, Vol. 41, No. 3, pp. 223-37.

Guerrero, H. (2010), Excel data analysis : modeling and simulation (Heidelberg; New York: Springer) $\mathrm{xv}, 338 \mathrm{p}$.

HRW [2013], 'Troubled water: Burst pipes, contaminated wells, and open defecation in Zimbabwe's capital', (Human Rights Watch).

IFRC [2009], 'Operations update - Zimbabwe: Cholera'.

Kovács, G. and Spens, K.M. (2007), "Humanitarian logistics in disaster relief operations", International Journal of Physical Distribution \& Logistics Management, Vol. 37, No. 2, pp. 99-114.

Lu, S.C.H., Ramaswamy, D., and Kumar, P.R. (1994), " Efficient scheduling policies to reduce mean and variance of cycle-time in semiconductor manufacturing plants", Semiconductor Manufacturing, IEEE Transaction, Vol. 7, No. 3, pp. 374-388

Mather, D. (1999), "A Framework for Building Spreadsheet Based Decision Models", The Journal of the Operational Research Society, Vol. 50, No. 1, pp. 70-74.

MSF-OCA [2008], 'Supply guideline', in MSF-OCA (ed.), (Amsterdam: MSF-OCA), pp. 263.

MSF [2008], 'Zimbabwe: MSF responds to worst cholera outbreak in years'. available at http://www.msf.ca/en/article/zimbabwe-msf-responds-worst-cholera-outbreak-years (accessed 10 October 2013) 
MSF [2010], 'Clinical guidelines - diagnosis and treatment manual for curative programmes in hospitals and dispensaries', (MSF Reference Books; Paris: Médecins Sans Frontières).

MSF [2013], 'What is a cholera treatment centre (CTC)?', (Médecins Sans Frontières).Murray S. (2005) How to deliver on the promises: Supply chain logistics: Humanitarian agencies are learning lessons from business in bringing essential supplies to regions hit by the tsunami. Financial Times (January 7):9.

Rawls, C.G. and Turnquist, M.A. (2011), "Pre-positioning planning for emergency response with service quality constraints", Or Spectrum, Vol. 33, No. 3, pp. 481-98.

Richardson, D., de Leeuw, S., and Vis, I. (2010), "Conceptualising Inventory Prepositioning in the Humanitarian Sector", in L. Camarinha-Matos, X. Boucher, and H. Afsarmanesh (eds.), Collaborative Networks for a Sustainable World (IFIP Advances in Information and Communication Technology, 336: Springer Boston), pp. 149-56.

Salmeron, J., and Apte, A. (2010), "Stochastic optimization for natural disaster asset prepositioning", Production and Operations Management, Vol. 19, No. 5, pp. 561-574.

Sheffi, Y. (2001), "Supply chain management under the threat of internatioal terrorism", The International Journal of Logistics Management, Vol. 12, No. 2, pp 1-12.

Tomasini, R.M. and Van Wassenhove, L.N. (2009), "From preparedness to partnerships: case study research on humanitarian logistics", International Transactions in Operational Research, Vol. 16, No. 5, pp. 549-59.

Van Wassenhove, L.N. (2006), "Humanitarian aid logistics: supply chain management in high gear", Journal of Operational Research Society, Vol. 57, No. 5, pp. 475-89.

WHO [2004], 'First steps for managing an outbreak of acute diarrhoea'. (World Health Organization).

WHO [2008], 'Global Alert and Response - Cholera in Zimbabwe', (World Health Organization). WHO [2010], ' Epidemiological Bulletin Number 40', (World Health Organization).

Zeng, A. Z., and Rossetti, C. (2003),"Developing a framework for evaluating the logistics costs in global sourcing processes: An implementation and insights", International Journal of Physical Distribution \& Logistics Management, Vol. 33, No. 9, pp. 785-803 